In conclusion, we are aware that lung donors who died from hypoxemia due to severe pulmonary embolism are high-risk donors and, thus, should be evaluated for transplantation very carefully. However, they should not be rejected as potential lung donors just by the diagnosis because extended evaluation strategies combined with the opportunity of retrograde flush perfusion might help to ultimately retrieve well-functioning lung grafts, especially for patients who have reached a disease state that may not allow them to wait for the next organ offer. Because there are no reports either on the use of lung grafts from donors with pulmonary embolism nor on evaluation strategies or technical aspects in the literature, we believe it was appropriate to report on our initial experience.

\section{References}

1. De Meester J, Smits JM, Persijn GG, Haverich A. Listing for lung transplantation: life expectancy and transplant effect, stratified by the type of end-stage lung disease, the Eurotransplant experience. $J$ Heart Lung Transplant. 2001;20:518-24.

2. Steen S, Sjoberg T, Pierre L, Liao Q, Eriksson L, Algotsson L. Transplantation of lungs from a non-heart-beating donor. Lancet. 2001;357: 825-9.

3. Barr ML, Baker CJ, Schenkel FA, et al. Living donor lung transplantation: selection, technique, and outcome. Transplant Proc. 2001;33: 3527-32.

4. Waddell TK, de Perrot M, Pierre A, Keshavjee S, Edwards LB. Impact of donor smoking on survival after lung transplantation. J Heart Lung Transplant. 2003;22(Suppl 1):S114 (Abstract 127).

5. Hopkins PMA, Luckraz H, Wallwork J. Successful outcome in lung transplant recipients who receive organs from donors with rapid onset of fatal asthma. J Heart Lung Transplant. 2003;22(Suppl 1):S112 (Abstract 120).

6. de Perrot M, Waddell TK, Shargall Y, D'Ovidio F, Pierre A, Keshavjee S. Lung transplantation with donors 60 years of age and older. J Heart Lung Transplant. 2003;22(Suppl 1):S87 (Abstract 42).

7. Pierre A, Sekine Y, Hutcheon MA, Waddell TK, Keshavjee S. Marginal donor lungs: a reassessment. J Thorac Cardiovasc Surg. 2002;123: 421-7.

\title{
Isolated persistent fifth aortic arch with systemic-to-pulmonary arterial connection
}

\author{
Mao-Sheng Hwang, MD, ${ }^{a, c}$ Yu-Sheng Chang, MD, , Jaw-Ji Chu, MD, ${ }^{\text {b,d }}$ and Wen-Jen Su, MD, ${ }^{\text {a,c }}$ Taoyuan, Taiwan
}

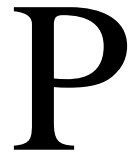

ersistent fifth aortic arch (PFAA) is thought to be an extremely rare congenital heart disease (CHD). All previously reported cases were associated with major cardiac anomalies and diagnosed coincidentally. ${ }^{1}$ Moreover, its presence was usually beneficial to the associated cardiac anomalies. We report here a unique case of isolated PFAA (without associated cardiac anomaly) with systemic-to-pulmonary arterial connection, which caused severe congestive heart failure (CHF) in a 2-month-old male infant.

\section{Clinical Summary}

A 2-month-old male infant weighing $3940 \mathrm{~g}$ was referred to our hospital for evaluation of a suspected atypical huge patent ductus arteriosus (PDA). He was the product of a 39-week gestation with

\footnotetext{
From the Departments of Cardiology ${ }^{\mathrm{a}}$ and Cardiac Surgery, ${ }^{\mathrm{b}}$ Chang Gung Children's Hospital, and Departments of Pediatrics ${ }^{\mathrm{c}}$ and Surgery, ${ }^{\mathrm{d}}$ Chang Gung University, Taoyuan, Taiwan.

Received for publication April 4, 2003; accepted for publication June 18, 2003.

Address for reprints: Wen-Jen Su, MD, Department of Cardiology, Chang Gung Children's Hospital, 5-7 Fu-Shin Street, Kweishan, Taoyuan 333, Taiwan (E-mail: hwaien2003@yahoo.com.tw).

J Thorac Cardiovasc Surg 2003;126:1643-4

Copyright $\odot 2003$ by The American Association for Thoracic Surgery $0022-5223 / 2003 \$ 30.00+0$

doi:10.1016/S0022-5223(03)00954-1
}

a birth weight of $3480 \mathrm{~g}$. He presented with severe $\mathrm{CHF}$ and failure to thrive. Chest radiographs revealed marked cardiomegaly, increased pulmonary vascular markings, pulmonary edema, and a convex pulmonary artery segment. The electrocardiogram demonstrated biventricular hypertrophy. A repeat echocardiogram done at our institution showed the segmental combination of solitus normal heart $\{\mathrm{S}, \mathrm{D}, \mathrm{S}\}(\mathrm{S}=$ visceroatrial situs solitus, $\mathrm{D}=\mathrm{D}$ ventricular loop, $\mathrm{S}=$ conotruncus solitus); dilated left atrium, left ventricle, and pulmonary arteries; normal left-sided aortic arch; and preserved ventricular performance. From the parasternal shortaxis view, a continuous, turbulent flow was detected at the bifurcation of the pulmonary trunk, which was not typical for PDA flow. From the modified suprasternal long-axis view, we detected a huge vessel originating from the left anterior aspect of distal ascending aorta (AsAo) but proximal to the transverse aortic arch (Figure 1) and connecting to the superior margin of the bifurcation of the pulmonary trunk. Isolated persistent fifth aortic arch with systemic-to-pulmonary arterial connection was suspected. Contrast computed tomographic 3-dimensional reconstruction of the heart and great vessels and ascending aortogram confirmed the diagnosis. Hemodynamic data revealed large left-to-right shunt (pulmonary/systemic blood flow ratio $>4$ ) and severe pulmonary hypertension (pulmonary/systemic systolic blood pressure ratio $=$ 1). The patient then underwent successful surgical ligation of this abnormal vessel through median sternotomy.

\section{Discussion}

Persistent fifth aortic arch is thought to be an extremely rare CHD because the fifth aortic arch almost always involutes during normal 


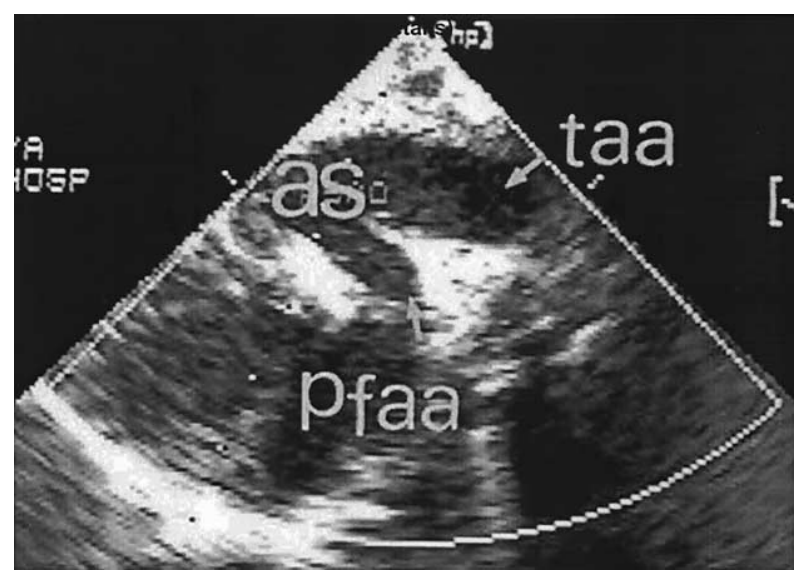

Figure 1. Modified suprasternal long-axis echocardiogram shows the persistent fifth aortic arch (pfaa) originating from the distal ascending aorta (as) but proximal to the transverse aortic arch (taa) and connecting to the superior margin of the bifurcation of the pulmonary trunk (not shown).

embryologic development. However, if it persists, an abnormal vessel originating from the distal AsAo proximal to the innominate artery will be formed, ${ }^{2}$ and it can manifest itself in many different congenital vascular malformations according to the intrinsic different embryologic maldevelopment. These include double-lumen aortic arch, subclavian artery as the first branch of the aortic arch, systemic-to-pulmonary arterial connection, systemic-to-systemic arterial connection. ${ }^{3}$ Therefore, it is probably not so rare if we include the asymptomatic, isolated, not yet diagnosed doublelumen aortic arch and subclavian artery as the first branch of the aortic arch.
All previously reported cases were associated with major CHD, such as pulmonary atresia, tricuspid atresia, coarctation of aorta, interrupted aortic arch, ventricular septal defect, or PDA, etc. ${ }^{1}$ The PFAA is usually hemodynamically beneficial or not harmful to the associated CHD and is diagnosed coincidentally. ${ }^{1}$ For example, double-lumen aortic arch is beneficial to the associated coarctation of aorta or interrupted aortic arch, and systemic-to-pulmonary arterial connection is beneficial to the associated pulmonary atresia or tricuspid atresia. ${ }^{1}$ Isolated double-lumen aortic arch or subclavian artery as the first branch of the aortic arch is not harmful to humans. ${ }^{4,5}$ However, our unique case with systemic-to-pulmonary arterial connection did not have any associated cardiovascular anomaly, and this isolated PFAA resulted in large left-to-right shunt, severe pulmonary hypertension, and CHF. Its clinical presentation was quite similar to huge PDA and thus might be misdiagnosed due to its rarity.

\section{References}

1. Gerlis LM, Dickinson DF, Wilson N, Gibbs JL. Persistent fifth aortic arch. A report of two new cases and a review of the literature. Int J Cardiol. 1987; 16:185-92.

2. Van Praagh R, Van Praagh S. Persistent fifth arterial arch in man. Congenital double lumen aortic arch. Am J Cardiol. 1969;24:279-82.

3. Moes CAF. Vascular rings and related conditions. In: Freedom RM, Mawson JB, Yoo SJ, Benson LN, editors. Congenital heart disease: textbook of angiocardiography. Vol II, 1st ed. Armonk, NY: Futura Publishing Company; 1997. p. 975-9.

4. Geva T, Ray RA, Santini F, Van Praagh S, Van Praagh R. Asymptomatic persistent fifth aortic arch (congenital double-lumen aortic arch) in an adult. Am J Cardiol. 1990;65:1406-7.

5. Moes CAF, Benson LN, Burrows PE, Freedom RM, Williams W, Duckworth JWA. The subclavian artery as the first branch of the aortic arch. Pediatr Cardiol. 1991;12:39-43. 